\title{
Aortoduodenal fistula: Not always bleeding
}

\author{
John CT Wong MD¹, David C Taylor MD², Michael F Byrne MD
}

\section{CASE PRESENTATION}

A 73-year-old woman presented to a community hospital with three months of intermittent, followed by continuous epigastric pain. There was no gastrointestinal bleeding, nausea, vomiting or fever. A noncontrast abdominal computed tomography scan identified gas locules around an aortobifemoral bypass graft performed in 1992, with surrounding inflammatory fat stranding (Figure 1A). Graft infection was suspected. Metronidazole was prescribed with outpatient follow-up by a vascular surgeon who referred her for gastroscopy. At the third part of the duodenum, a wall defect $3 \mathrm{~cm} \times 2 \mathrm{~cm}$ in size was replaced by a yellow-coloured foreign body suspected to be the external surface of an aortic Dacron graft (Figure 1B). The aortoduodenal fistula was treated with an axillofemoral graft, removal of the infected graft and a duodenal-jejunostomy, in which the lateral wall defect at the junction of the third and fourth parts of the duodenum was closed with a loop of proximal jejunum (Figure 1C). Cultures from the excised graft had growth of Candida lusitaniae and Streptococcus constellatus. Antimicrobials were commenced, with recovery in two months.

\section{DISCUSSION}

Secondary aortoenteric fistulas, occurring at a rate of $0.3 \%$ to $2 \%$ and usually three to five years postoperatively, are attributed to arterial pulsations against adjacent duodenum without interposed tissue or chronic low-grade graft infection, usually of intra-abdominal commensal organisms through a biofilm (1-3). Although gastrointestinal bleeding is the most frequent symptom, $>60 \%$ of patients with fistulas may not exhibit endoscopic signs of bleeding similar to our patient (4). Luminal obstructive symptoms and sepsis from graft infections should also raise suspicions of a fistula, which should be promptly investigated by endoscopy visualizing the third/fourth parts of the duodenum and contrast computed tomography scan showing characteristic findings $(3,5)$. Timely management, either surgically or by endovascular stent placement in high-risk operative patients, is essential for this highly morbid complication (3). There needs to be a low threshold to investigate aortoenteric fistulas by endoscopy.

DISCLOSURES: The authors have no financial disclosures or conflicts of interest to declare.

\section{REFERENCES}

1. Armstrong PA, Back MR, Wilson JS, Shames ML, Johnson BL, Bandyk DF. Improved outcomes in the recent management of secondary aortoenteric fistula. J Vasc Surg 2005;42:660-6.

2. Pipinos II, Carr JA, Haithcock BE, Anagnostopoulos PV, Dossa CD, Reddy DJ. Secondary aortoenteric fistula. Ann Vasc Surg 2000;14:688-96.

3. Mathias J, Mathias E, Jausset F, et al. Aorto-enteric fistulas: A physiopathological approach and computed tomography diagnosis. Diagn Interv Imaging 2012;93:840-51.

4. Busuttil SJ, Goldstone J. Diagnosis and management of aortoenteric fistulas. Semin Vasc Surg 2001;14:302-11.

5. Tacchini S, Nicoletti R, Ghio D, et al. CT findings of secondary aorto-enteric fistulae. Radiol Med 2005;110:492-500.
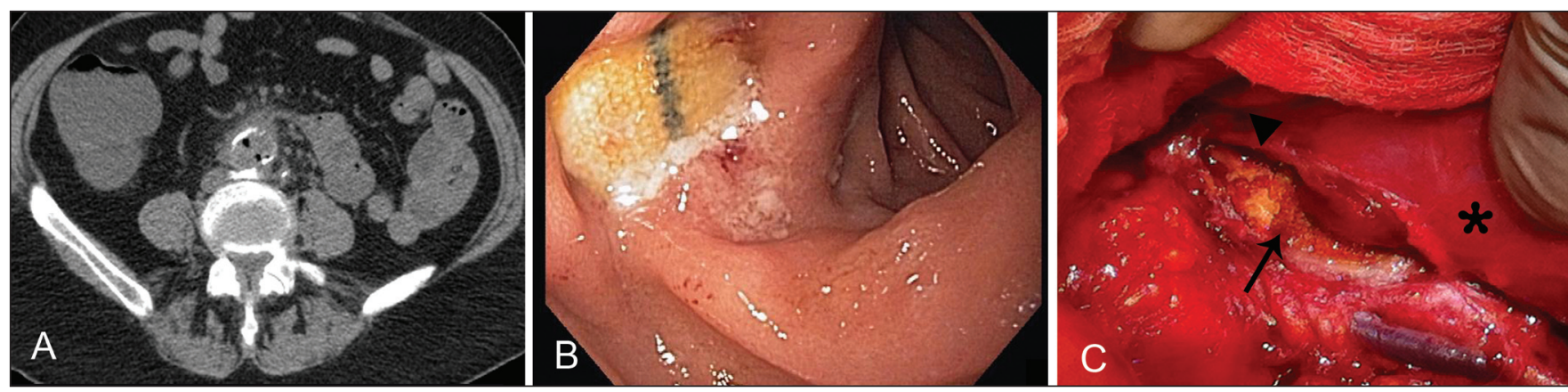

Figure 1) A Noncontrast computed tomography scan of the abdomen showing an axial view of gas locules around an aortobifemoral bypass graft. B Endoscopic view of a wall defect in the third/fourth part of the duodenum replaced by an aortic Dacron graft. C Intraoperative image showing defect (arrowhead) in the lateral wall of the fourth part of the duodenum (asterisk) and the bypass graft (arrow)

${ }^{1}$ Division of Gastroenterology, Department of Medicine; ${ }^{2}$ Division of Vascular Surgery, Department of Surgery, University of British Columbia, Vancouver, British Columbia

Correspondence: Dr Michael F Byrne, Division of Gastroenterology, Department of Medicine, University of British Columbia, 5153-2775 Laurel Street,

Vancouver, British Columbia V5Z 1M9. Telephone 604-875-5640, fax 604-875-5378, e-mail michael.byrne@vch.ca

Received for publication March 17, 2013. Accepted May 12, 2013 


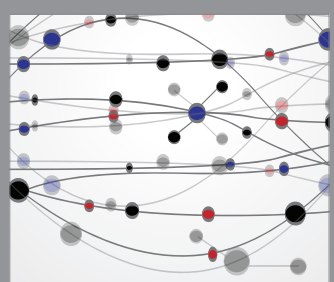

The Scientific World Journal
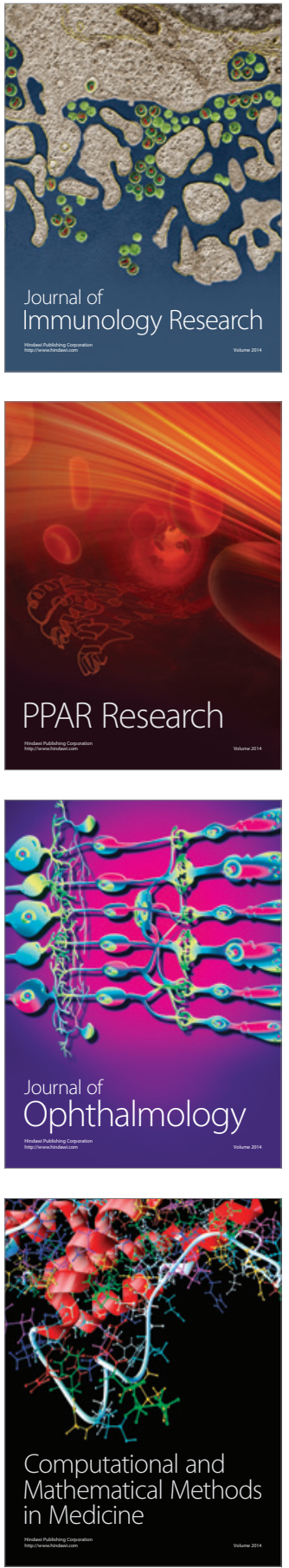

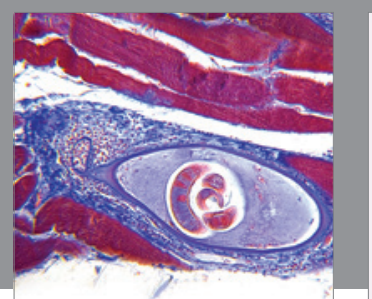

Gastroenterology Research and Practice

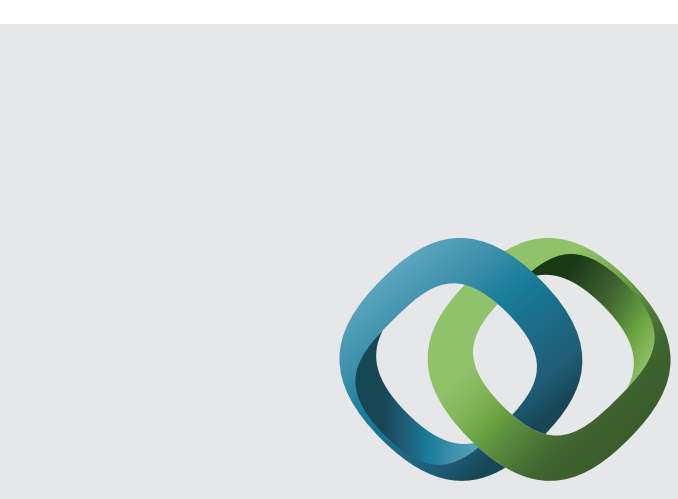

\section{Hindawi}

Submit your manuscripts at

http://www.hindawi.com
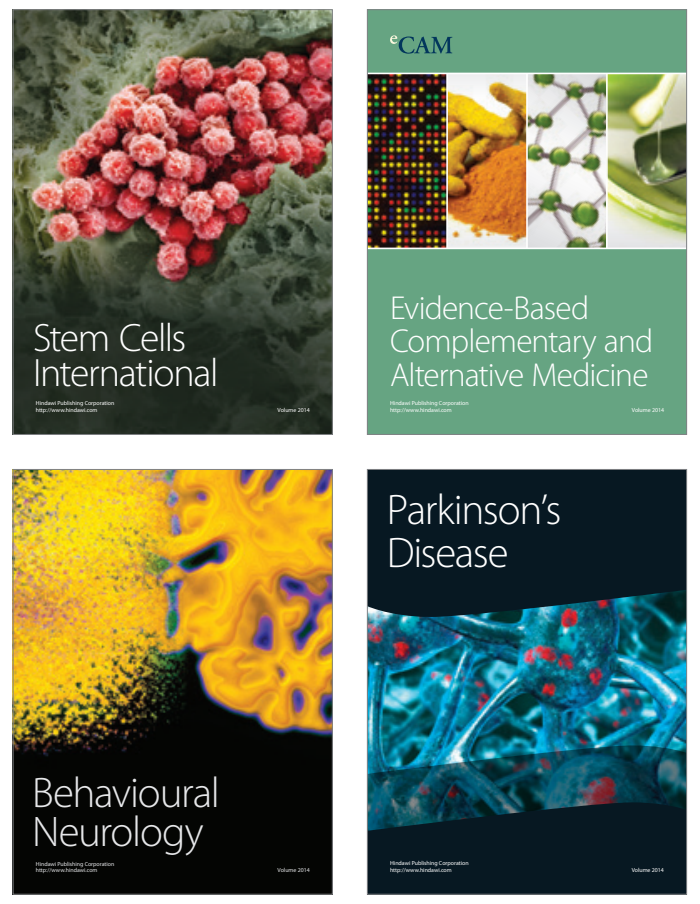
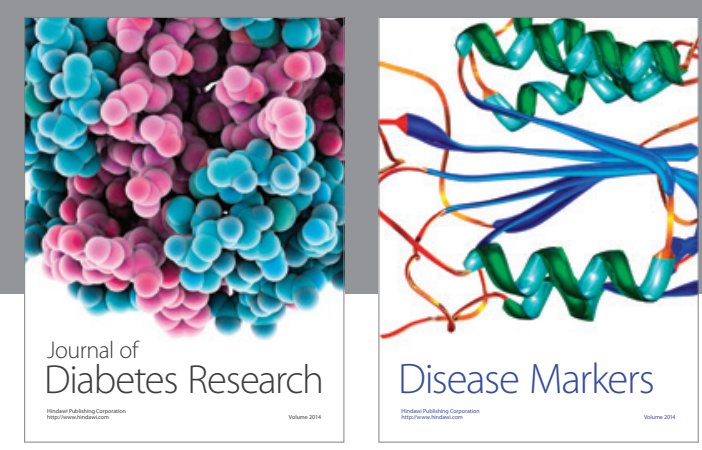

Disease Markers
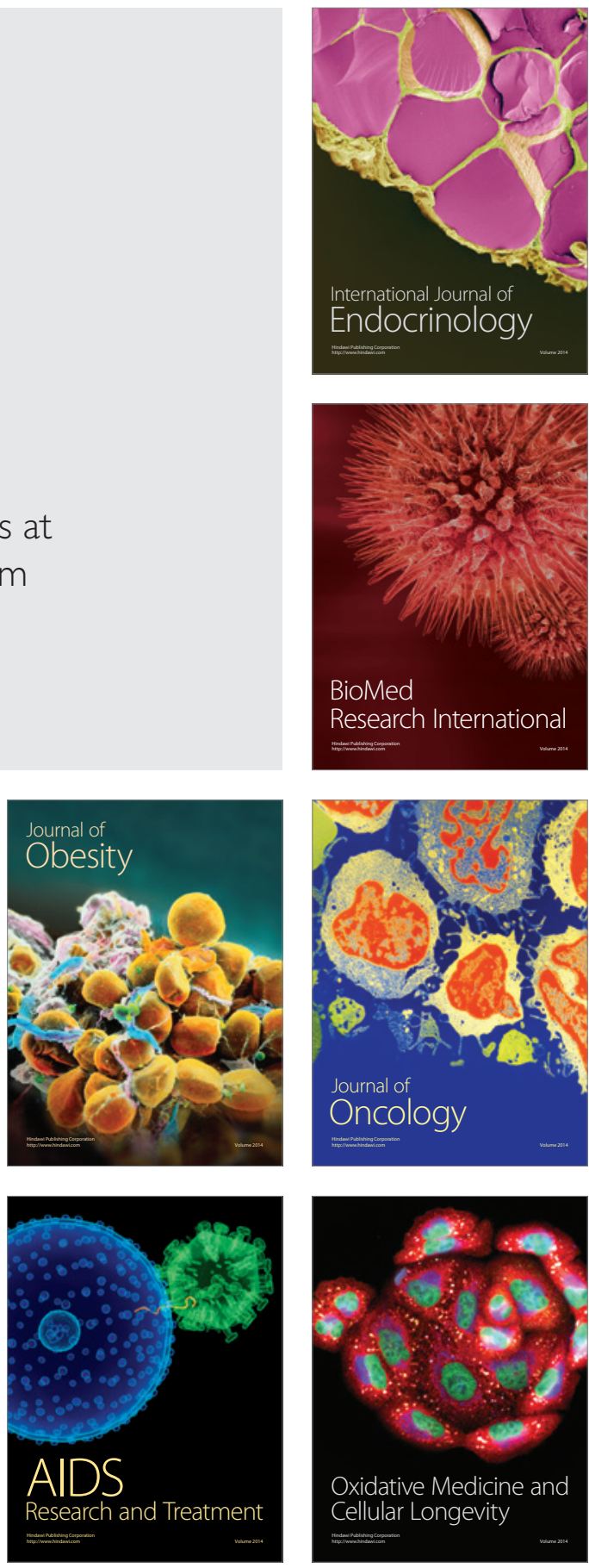